\title{
Rancang Bangun Sistem Conditioning Udara Berbasis IoT pada Studi Kasus Tanaman Selada Hidroponik
}

\author{
(Design and Development of Air Conditioning System Based on IoT in Case Study \\ Hydroponic Lettuce Plant)
}

\author{
Anak Agung Angga Dwipa*, I Gede Putu Wirarama Wedashwara W, Ariyan Zubaidi. \\ Program Studi Teknik Informatika, Fakultas Teknik, Universitas Mataram \\ J1. Majapahit 62, Mataram, Lombok NTB, INDONESIA \\ Email: anggaagung949@gmail.com, [wirarama, zubaidi13]@unram.ac.id
}

*Penulis korespondensi

\begin{abstract}
Air temperature and humidity as well as water temperature are very important environment variables in planting DFT hydroponic lettuce plants in a greenhouse. Controlling and monitoring the temperature and humidity still done manually by farmers. This problem can be solved by building an air conditioning system that implements the concept of the Internet of Things, which plays a role in automation control of actuators, and the MQTT protocol as its data communication medium. Based on the test results, the system has been able to perform measurement and conditioning of air temperature, humidity and water temperature in the greenhouse automatically. Comparison of test and observation result data with sunny weather conditions, showing that the average and maximum value of air and water temperature in the test are lower compared to the observation data. While the average and minimum value of humidity in the test are higher than the observation data.
\end{abstract}

Key words: Lettuce, DFT hydroponic, Greenhouse, Internet of Things, MQTT.

\section{PENDAHULUAN}

Seiring dengan meningkatnya kesadaran akan kebutuhan gizi menyebabkan bertambahnya permintaan dan kebutuhan masyarakat akan sayuran, salah satunya adalah pada tanaman sayuran selada. Selada merupakan salah satu komoditi hortikultura yang memiliki nilai komersial yang cukup baik [1].

Berdasarkan Badan Pusat Statistik (BPS) secara nasional digambarkan bahwa ekspor selada pada tahun 2002 adalah 47.942 ton meningkat menjadi 55.710 ton pada tahun 2003. Salah satu alternatif dalam meningkatkan produktivitas tanaman selada adalah dengan membudidayakan tanaman secara hidroponik. Selain tumbuh di dataran tinggi atau daerah pegunungan, tanaman selada juga dapat tumbuh optimal di dataran rendah atau daerah perkotaan dengan menerapkan metode bercocok tanam hidroponik sistem DFT (Deep Flow Technique) di dalam sebuah greenhouse [2].

Suhu dan kelembaban merupakan variabel lingkungan yang sangat penting untuk diperhatikan dalam bercocok tanam tanaman selada hidroponik di dalam sebuah greenhouse. Pertumbuhan selada akan optimal pada kisaran suhu udara $25{ }^{\circ} \mathrm{C}$ sampai $28{ }^{\circ} \mathrm{C}$ dan kelembaban berkisar antara $65 \%$ sampai $78 \%$ [3]. Kondisi suhu dan kelembaban udara yang tidak stabil menyebabkan tanaman menjadi layu dan berkembangnya bibit penyakit sehingga pertumbuhan pada tanaman selada menjadi tidak optimal. Kondisi suhu udara juga berpengaruh terhadap kondisi suhu air pada media tanam hidroponik. Suhu air yang stabil juga sangat penting agar tanaman selada dapat menyerap unsur hara dengan maksimal. Pengendalian suhu dan kelembaban udara pada pertanian selada hidroponik di dalam sebuah greenhouse umumnya masih dilakukan secara manual oleh petani, dimana petani harus melakukan penyiraman pada daun tanaman selada untuk menjaga suhu dan kelembabannya agar tetap stabil. Selain itu, petani masih menggunakan feeling dan perkiraan untuk memantau kondisi suhu dan kelembaban pada greenhouse, sehingga petani tidak mengetahui pasti waktu yang tepat untuk melakukan penyiraman, seperti yang diterapkan pada tempat pembudidayaan tanaman selada hidroponik Mustika Hydrofarm yang berlokasi di lingkungan Sweta Kecamatan Cakranegara. Berdasarkan permasalahan tersebut maka diperlukan suatu sistem conditioning udara pada tanaman selada hidroponik di dalam sebuah greenhouse, sehingga dapat mempermudah petani dalam melakukan pengendalian dan pemantauan suhu dan kelembaban pada tanamannya.

Sistem conditioning udara merupakan sistem yang dirancang untuk melakukan pengkondisian atau menstabilkan suhu dan kelembaban udara pada suatu area tertentu. Pada penelitian ini, sistem conditioning udara yang dibangun menerapkan konsep IoT (Internet of Things) yaitu memanfaatkan koneksivitas internet untuk interaksi antara mikrokontroler dan sistem web yang akan mengendalikan kipas dan pompa sprinkler secara otomatis serta sebagai media pemantauan dan pengaturan parameter ambang batas suhu dan kelembaban udara serta suhu air pada tanaman selada hidroponik di dalam sebuah 
greenhouse. Kemudian penerapan protokol MQTT (Message Queue Telemetry Transport) sebuah protokol komunikasi yang bersifat client-server, agar terciptaanya komunikasi data secara dua arah dengan cepat perangkat dan sistem web [4]. Protokol MQTT cocok digunakan karena memiliki delay pengiriman data dengan kualitas yang baik, karena menghasilkan rata - rata delay sebesar 0.028183014 detik dan packet loss dari publisher ke server sebesar 0\% pada studi kasus sistem parkir Universitas Brawijaya [5].

\section{TinJAUAN PUSTAKA}

Penelitian terkait sistem monitoring maupun pengendalian suhu dan kelembaban udara ataupun suhu air pernah dilakukan. Pertama penelitian tentang sistem kontrol suhu pada sebuah greenhouse berukuran panjang 2 meter, lebar 2 meter dan tinggi 2 meter. Pada penelitian ini media pemantauannya yang hanya menggunakan modul Liquid Crystal Display (LCD) 16x2 sehingga proses pemantauan belum dapat dilakukan secara jarak jauh dan belum menerapkan protokol tertentu dalam komunikasi datanya [6].

Penelitian kedua tentang sistem monitoring kelembaban tanah, kelembaban udara dan suhu pada lahan pertanian. Penelitian ini telah dapat mendeteksi suhu, kelembaban udara dan kelembaban tanah dengan baik dengan komunikasi data secara realtime menggunakan protokol MQTT serta hasil monitoring ditampilkan pada webserver thingsboard [7].

Penelitian ketiga tentang sistem pengendalian suhu dan kelembaban pada tanaman selada dengan sistem aeroponik. Penelitian ini menggunakan modul Liquid Crystal Display (LCD) sebagai media monitoring dan tidak menggunakan protokol dalam komunikasi datanya, sehingga proses pemantauan belum dapat dilakukan dengan jarak jauh [3].

Penelitian keempat tentang sistem monitoring parameter suhu pada tanaman cabe merah di dalam sebuah greenhouse berukuran panjang 3,6 meter, lebar 3 meter dan tinggi 3 meter. Pada penelitian ini hanya berfokus pada proses monitoring, sehingga tidak dapat melakukan pengendalian atau pengkondisian suhu pada greenhouse dan tidak menggunakan protokol dalam komunikasi datanya [8].

Penelitian kelima tentang tentang pendingin otomatis akuarium dengan menggunakan sensor suhu air DS18B20 tipe waterproof. Pada penelitian ini media monitoring hanya menggunakan serial monitor pada aplikasi Arduino IDE dan belum menggunakan protokol tertentu dalam komunikasi datanya [9].

Dari beberapa literatur di atas, sistem yang akan dibuat untuk melakukan pemantauan dan pengkondisian suhu dan kelembaban udara serta suhu air tanaman selada hidroponik di dalam sebuah greenhouse. Sistem berbasis web dengan protokol MQTT sebagai protokol komunikasi datanya yang berfungsi sebagai media monitoring dan pengaturan parameter suhu dan kelembaban udara serta suhu air.

\section{Metode PeRANCANGAN}

\section{A. Perancangan Perangkat Keras}

Pada tahap perancangan perangkat keras, akan dilakukan perancangan terhadap arsitektur sistem dan gambaran rangkaian elektronika dari sistem conditioning udara berbasis IoT pada studi kasus tanaman selada hidroponik.

\section{A.1. Arsitektur Sistem}

Gambaran dari arsitektur sistem conditioning udara berbasis IoT pada studi kasus tanaman selada hidroponik yang akan dibangun dapat dilihat pada Gambar 1.

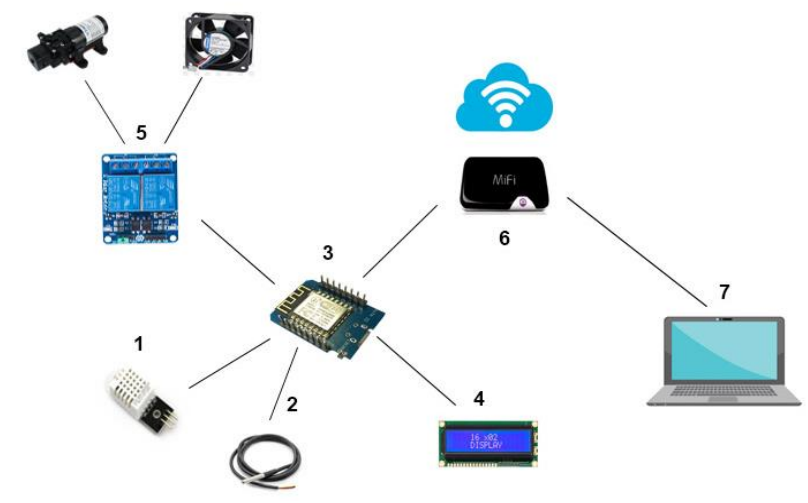

Gambar 1. Arsitektur Sistem

Arsitektur dari sistem conditioning udara berbasis IoT pada studi kasus tanaman selada hidroponik yang akan dibuat pada penelitian ini, terdiri dari beberapa perangkat yang saling terhubung. Berikut merupakan penjelasan dari masing-masing proses yang terdapat pada Gambar 1.

1. Sensor suhu dan kelembaban DHT22 pada rangkaian elektronika, digunakan untuk mendeteksi terjadinya perubahan suhu dan kelembaban udara di sekitar greenhouse tanaman selada hidroponik.

2. Sensor suhu air DS18B20 pada rangkaian elektronika digunakan untuk mendeteksi terjadinya perubahan suhu air pada media tanam hidroponik.

3. Mikrokontroler Wemos D1 Mini, digunakan untuk mengambil data dari sensor, menampilkan hasil pembacaan sensor ke LCD, melakukan perintah ke relay serta mengirim data dengan protokol MQTT.

4. LCD $16 \times 2$ karakter akan menampilkan pembacaan suhu dan kelembaban udara serta suhu air dari sensor dan mikrokontroler.

5. Relay module 2 channel pada rangkaian elektronika, digunakan untuk melakukan pengontrolan yaitu menyalakan atau mematikan pompa sprinkler dan kipas angin. Pompa sprinkler dan kipas angin akan menyala dan mati secara otomatis, yang dikendalikan oleh relay sesuai dengan perintah dari mikrokontroler.

6. MiFi (Mobile Wi-Fi) sebagai router dan wireless modem untuk sarana penyedia koneksi internet agar mikrokontroler dapat terhubung dan bertukar data dengan sistem web melalui internet. 
7. Sistem berbasis web, digunakan sebagai penerima data dari rangkaian elektronika yang dibuat untuk ditampilkan serta untuk pengaturan parameter suhu dan kelembaban udara serta suhu air yang dilakukan oleh pengguna sistem.

\section{A.2. Rangkaian Elektronika}

Gambaran dari rangkaian elektronika sistem conditioning udara berbasis IoT pada studi kasus tanaman selada hidroponik yang akan dibangun dapat dilihat pada Gambar 2. Rangkaian ini terdiri dari lima perangkat keras yang dihubungkan menjadi sebuah perangkat sistem conditioning udara yang terdiri dari Wemos D1 Mini sebagai mikrokontroler, sensor DHT22, sensor DS18B20, LCD 16x2, modul relay, pompa sprinkler dan kipas angin sebagai aktuatornya.

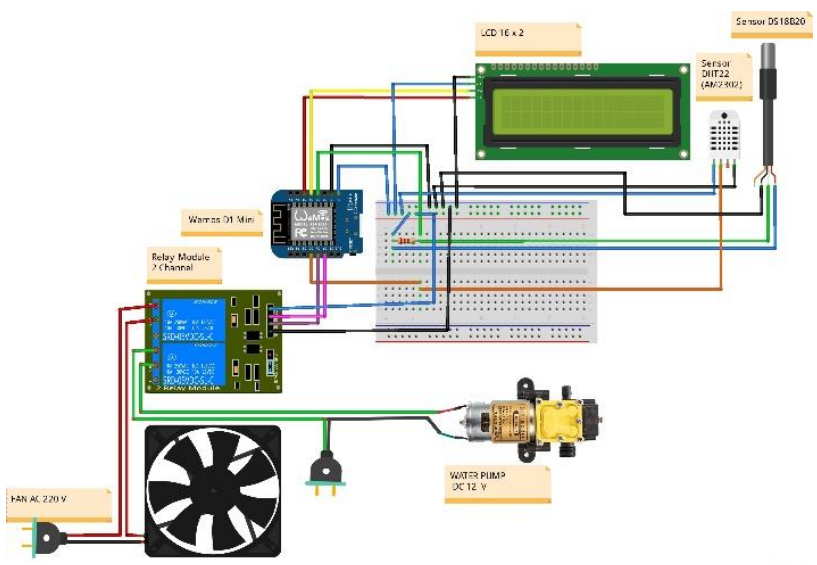

Gambar 2. Rangkaian Elektronika Sistem

\section{B. Perancangan Perangkat Lunak}

Pada tahap perancangan perangkat lunak, dilakukan perancangan web sistem conditioning udara. Selain merancang web, pada tahap ini juga akan dilakukan pemrograman untuk komunikasi data antara web dan perangkat IoT dengan protokol MQTT.

\section{B.1. Use Case Diagram}

Rancangan use case diagram dari sistem conditioning udara berbasis IoT pada studi kasus tanaman selada hidroponik dapat dilihat pada Gambar 3.

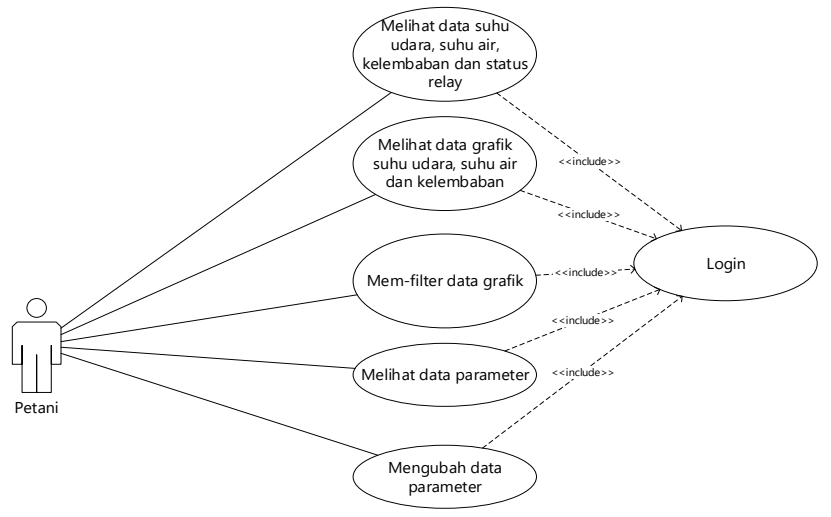

Gambar 3. Use Case Diagram Sistem
Terdapat enam aktivitas dan satu aktor yang menggunakan sistem yaitu petani pada sistem conditioning udara berbasis IoT pada studi kasus tanaman selada hidroponik yang dibangun. Petani dapat melakukan aktivitas melihat data suhu udara, suhu air, kelembaban dan status relay; melihat dan mem-filter data grafik suhu udara, suhu air dan kelembaban udara; melihat data parameter serta mengubah data parameter. Aktivitas melihat data suhu udara, kelembaban, suhu air dan status relay; melihat dan mem-filter data grafik suhu udara, suhu air dan kelembaban udara; melihat data parameter serta mengubah data parameter hanya dapat dilakukan apabila petani telah melakukan aktivitas login terlebih dahulu pada sistem.

\section{B.2. Entity Relationship Diagram}

Rancangan entity relationship diagram dari sistem conditioning udara berbasis IoT pada studi kasus tanaman selada hidroponik dapat dilihat pada Gambar 4.

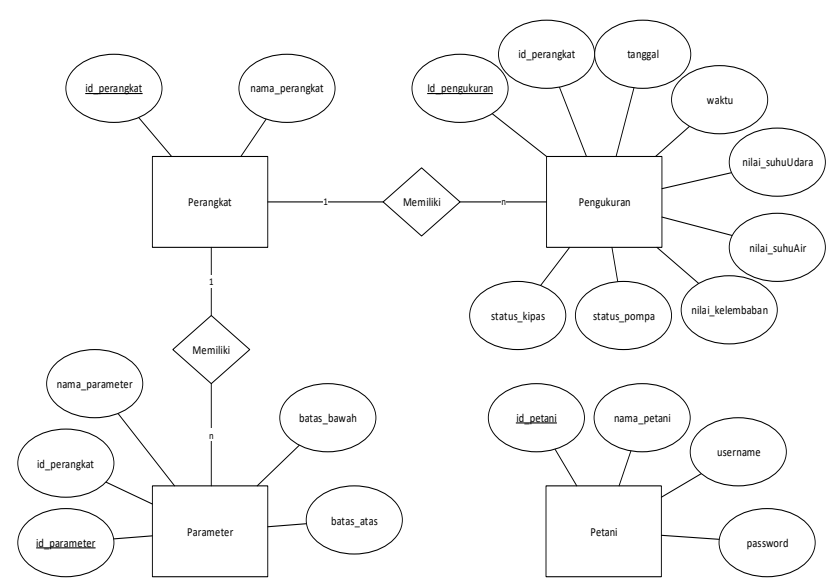

Gambar 4. Entity Relationship Diagram Sistem

Terdapat empat entitas pada sistem, seperti yang ditunjukkan pada Gambar 4 yaitu, entitas petani, perangkat, pengukuran dan parameter. Pada entitas petani memiliki atribut id_petani, nama_petani, username dan password. Pada entitas perangkat terdiri dari atribut id_perangkat dan nama_perangkat. Kemudian pada entitas pengukuran memiliki atribut id_pengukuran, id_perangkat, tanggal, waktu, nilai_suhuUdara, nilai_suhuAir, nilai_kelembaban, status_pompa dan status kipas Sedangkan pada entitas parameter memiliki atribut id_parameter, id_perangkat, nama_parameter, batas_bawah dan batas_atas.

\section{B.3. Komunikasi MQTT Sistem}

Rancangan dari komunikasi MQTT sistem, pada sistem conditioning udara berbasis IoT pada studi kasus tanaman selada hidroponik dapat dilihat pada Gambar 5. Komunikasi MQTT sistem, pada sistem conditioning udara berbasis IoT pada studi kasus tanaman selada hidroponik yang terdiri dari dua alur proses komunikasi. Alur proses pertama merupakan proses publish data pengukuran sensor dan status relay dari mikrokontroler menuju MQTT broker. 


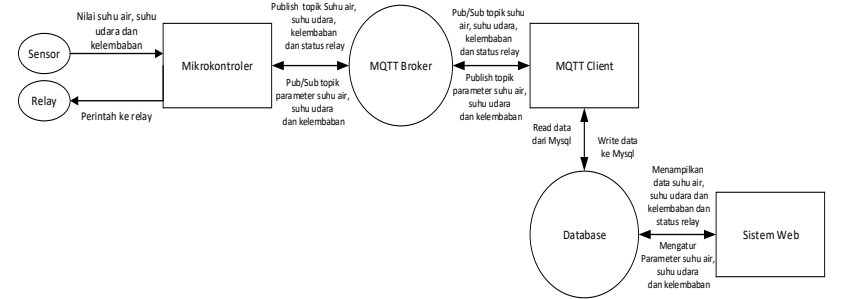

Gambar 5. Rancangan Komunikasi MQTT Sistem

Kemudian MQTT client yang berperan sebagai subscriber akan menerima data dan menyimpannya ke database dan selanjutnya akan ditampilkan ke sistem web. Sedangkan alur proses kedua merupakan proses publish data parameter ambang batas yang di-set oleh pengguna melalui sistem web. Kemudian MQTT client yang berperan sebagai publisher akan mem-publish data menuju ke MQTT broker. Selanjutnya mikrokontroler akan mensubscribe data tersebut dan akan memberi perintah ke relay sesuai dengan nilai ambang batas yang didapatkan.

\section{Observasi dan Kalibrasi Variabel Sensor}

Pada tahap observasi dan kalibrasi variabel sensor, akan dilakukan proses pengamatan, pencatatan dan penyesuaian data variabel sensor yaitu suhu, kelembaban udara dan suhu air. Observasi dilakukan pada sebuah greenhouse berukuran panjang 4 meter, lebar 3 meter dan tinggi 3 meter yang didampingi oleh praktisi atau petani selada hidroponik. Data yang didapatkan akan disimpan pada Microsoft excel dan akan dijadikan referensi dalam pengaturan nilai parameter ambang batas dalam pengkondisian suhu dan kelembaban udara serta suhu air.

\section{Implementasi Sistem}

Setelah tahap perancangan selesai dibuat, tahap selanjutnya adalah tahap implementasi dari sistem yang akan dibangun. Tahap implementasi ini akan dibagi menjadi tiga proses yaitu penyusunan perangkat keras, pembangunan kontrol aplikasi serta pembangunan sistem web dan protokol MQTT.

1. Pada tahap penyusunan perangkat keras, mikrokontroler Wemos D1 Mini, sensor suhu DHT22, sensor suhu air DS18B20, LCD dan relay module akan disusun menjadi satu rangkaian perangkat keras. Proses untuk merangkai alat ini disesuaikan dengan rancangan pada tahap rancangan perangkat keras sistem.

2. Pada tahap pembangunan kontrol aplikasi, rancangan kontrol aplikasi akan diimplementasikan ke dalam mikrokontroler Wemos D1 Mini menggunakan bahasa pemrograman $\mathrm{C}++$, melalui Arduino IDE sebagai alat bantu.

3. Pada tahap pembangunan sistem web dan protokol MQTT, web akan dihubungkan dengan wemos D1 Mini melalui protokol MQTT, guna melakukan monitoring dan pengaturan parameter ambang batas suhu dan kelembaban udara serta suhu air. Dalam pembuatan sistem berbasis web dibangun menggunakan HTML, PHP, MySQL, framework codeigniter dan bootstrap.

\section{E. Pengujian dan Evaluasi Sistem}

Pada tahap pengujian dan evaluasi sistem, dilakukan pengujian terhadap sistem yang sudah dibangun dan evaluasi dari hasil pengujian yang dilakukan tersebut. Pada penelitian ini teknik pengujian yang digunakan yaitu pegujian black box dan pengujian terhadap perangkat keras.

\section{E.1. Black box}

Pada pengujian black box dilakukan pada sistem berbasis web. Pengujian dilakukan untuk mengamati dan memeriksa fungsionalitas dari perangkat sistem berbasis web. Faktor yang diamati adalah fungsi-fungsi yang tidak benar atau hilang, kesalahan interface, kesalahan dalam akses database.

\section{E.2. Pengujian Perangkat Keras}

Pada pengujian perangkat keras ini dilakukan pada fungsionalitas dari perangkat IoT yang digunakan. Perangkat sudah berkerja dengan baik atau memiliki malfungsi sehingga menyebabkan hasil yang diinginkan dari alat tidak maksimal.

\section{HASIL DAN PEMBAHASAN}

\section{A. Realisasi Sistem}

Pada realisasi sistem ini, akan membahas hasil dari penelitian Rancang Bangun Sistem Conditioning Udara Berbasis IoT pada Studi Kasus Tanaman Selada Hidroponik. Realisasi dilakukan sesuai dengan tahap perancangan perangkat keras dan perangkat lunak. Pembahasan yang akan dijelaskan meliputi Realisasi penyusunan perangkat keras, Realisasi pembangunan control application, Realisasi tahap observasi dan kalibrasi variabel sensor, Realisasi pembangunan database, Realisasi pembangunan sistem berbasis web dan Realisasi pembangunan komunikasi protokol MQTT pada sistem.

\section{A.1. Realisasi Penyusunan Perangkat Keras}

Realisasi penyusunan perangkat keras dari Sistem Conditioning Udara Berbasis IoT pada Studi Kasus Tanaman Selada Hidroponik dapat dilihat pada Gambar 6 yang mengacu kepada rancangan perangkat keras pada Gambar 2.

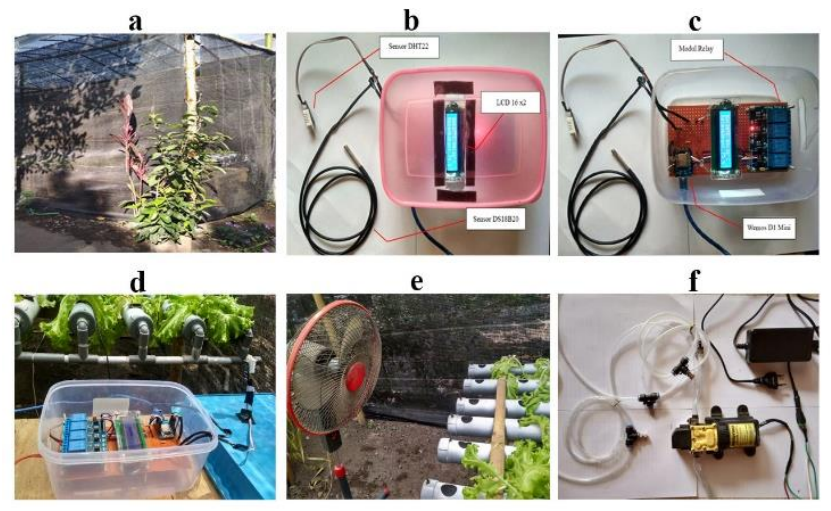

Gambar 6. Realisasi Penyusunan Perangkat Keras 
Pada tahap realisasi perangkat keras ini, perangkat dirangkai berdasarkan pada tahap perancangan yang telah dilakukan. Berdasarkan Gambar 6 terdapat lima perangkat keras yang dihubungkan menjadi sebuah perangkat sistem conditioning udara yang terdiri dari Wemos D1 Mini, sensor DHT22, sensor DS18B20, LCD 16x2, modul relay, pompa sprinkler dan kipas angin. Fungsi dari alat-alat tersebut adalah sebagai berikut:

- Gambar 6 a merupakan sebuah greenhouse yang menjadi tempat untuk diterapkannya Sistem Conditioning Udara berbasis IoT pada penelitian ini. Greenhouse Mustika Hydrofarm merupakan tempat pembudidayaan tanaman selada hidroponik, berlokasi di lingkungan Sweta, Kecamatan Cakranegara yang memiliki ukuran panjang 4 meter, lebar 3 meter dan tinggi 3 meter.

- Gambar 6 b merupakan realisasi perangkat keras tampak luar yang dapat dilihat terdiri dari sensor DHT22 untuk mengukur suhu dan kelembaban udara, sensor DS18B20 untuk mengukur suhu air dan modul LCD 16 × 2 sebagai media monitoring.

- Gambar 6 c merupakan realisasi perangkat keras tampak dalam yang dapat dilihat terdiri dari Wemos D1 Mini sebagai mikrokontroler dan relay module untuk menyalakan dan mematikan aktuator pompa sprinkler dan kipas angin pada sistem

- Gambar 6 d merupakan penempatan perangkat Sistem Conditioning Udara pada greenhouse.

- Gambar 6 e merupakan aktuator kipas angin yang digunakan untuk menurunkan tingkat suhu air pada media tanam tanaman selada hidroponik serta menurunkan tingkat suhu udara di sekitar greenhouse.

- Gambar 6 f merupakan aktuator pompa sprinkler yang digunakan untuk menaikkan tingkat kelembaban udara, yang bekerja dengan menyemprotkan air berupa embun halus disekitar ruang greenhouse dan membasahi daun - daun tanaman selada.

\section{A.2. Realisasi Pembangunan Control Application}

Dalam realisasi pembangunan control application bahasa yang digunakan adalah bahasa $\mathrm{C}$, dan IDE yang digunakan adalah Arduino IDE. Untuk membangun control application agar dapat terkoneksi dengan sensor DHT22, sensor DS18B20, modul LCD 16 x 2, modul relay serta berkomunikasi dengan broker melalui protokol MQTT. Realisasinya dapat dilihat pada Listing 1.

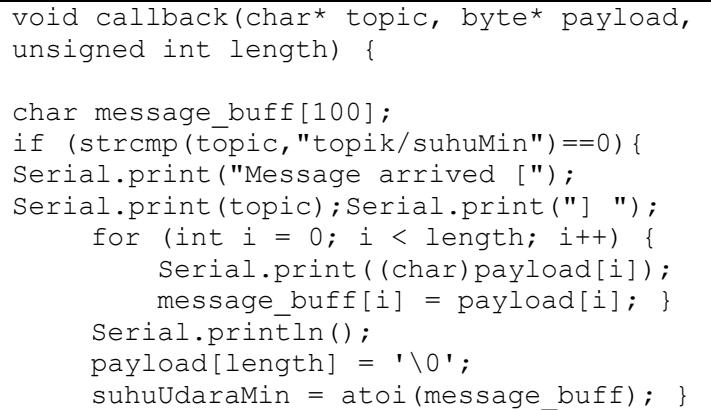

Listing 1. Source code method callback
Pada Listing 1, source code method void callback digunakan untuk menerima pesan atau payload pada sebuah topik yang telah di subscribe. Nilai pesan atau payload yang diterima merupakan nilai parameter ambang batas untuk suhu dan kelembaban udara serta suhu air.

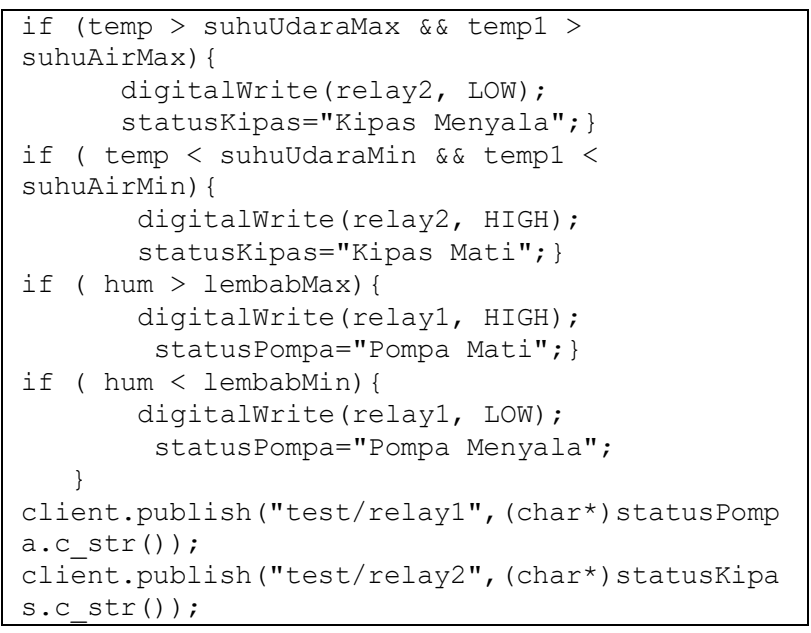

Listing 2. Source code keputusan relay

Pada Listing 2, source code keputusan relay digunakan untuk menentukan keputusan dalam mengaktifkan atau mematikan modul relay. Jika nilai suhu udara dan suhu air lebih besar dari ambang batas atas maka relay 2 aktif dan kipas angin dalam kondisi menyala. Jika nilai suhu udara dan suhu air lebih kecil dari ambang batas bawah relay 2 tidak aktif dan kipas angin dalam kondisi mati. Kemudian jika nilai kelembaban lebih besar dari ambang batas atas maka relay 1 tidak aktif dan pompa sprinkler dalam kondisi mati. Sedangkan jika nilai kelembaban lebih kecil dari ambang batas bawah maka artinya relay 1 aktif dan pompa sprinkler dalam kondisi menyala. Selain itu, terjadi juga proses mengirim data atau melakukan proses publish data status relay dalam bentuk data String sesuai dengan topik yang telah ditentukan.

\section{A.3. Realisasi Observasi dan Kalibrasi Variabel Sensor}

Pengambilan data pada tahap observasi dan kalibrasi variabel sensor ini dilakukan selama 1 minggu terhitung dari tanggal 15 Juli 2019 sampai 21 Juli 2019 mulai dari pukul 08.00 WITA sampai pukul 17.00 WITA. Hasil obervasi dan kalibrasi variabel sensor dapat dilihat pada Tabel I sampai Tabel III.

Tabel I merupakan nilai rata - rata, nilai maksimum dan nilai minimum suhu udara berdasarkan data hasil observasi yang telah dilakukan selama 1 minggu. Berdasarkan hasil observasi yang telah dilakukan tersebut, terdapat beberapa kondisi cuaca yang terjadi yaitu cerah berawan, cerah terik dan mendung. Pada hari ke -2 memiliki nilai suhu udara rata - rata terbesar dan nilai maksimum suhu udara terbesar dibandingkan dengan data pada hari - hari lainnya yaitu 30. $44^{\circ} \mathrm{C}$ dan $37^{\circ} \mathrm{C}$. Sedangkan pada hari ke -3 memiliki nilai suhu udara rata - rata terkecil, yaitu $26.95{ }^{\circ} \mathrm{C}$ dan pada hari ke - 4 memiliki nilai suhu udara maksimum terkecil dibandingkan dengan hari - hari lainnya, yaitu $30{ }^{\circ} \mathrm{C}$. 
TABEL I. RATA - RATA, MAKSIMUM DAN MINIMUM SUHU UDARA DATA OBSERVASI

\begin{tabular}{|c|c|c|c|c|c|}
\hline No & Hari & $\begin{array}{c}\text { Kondisi } \\
\text { Cuaca }\end{array}$ & $\begin{array}{c}\text { Suhu } \\
\text { Udara } \\
\text { Rata }- \\
\text { rata }\left({ }^{\mathbf{O}} \mathbf{C}\right)\end{array}$ & $\begin{array}{c}\text { Suhu } \\
\text { Udara } \\
\text { Maksimum } \\
\left({ }^{\mathbf{0}} \mathbf{C}\right)\end{array}$ & $\begin{array}{c}\text { Suhu } \\
\text { Udara } \\
\text { Minimum } \\
\left({ }^{\mathbf{O}} \mathbf{C}\right)\end{array}$ \\
\hline 1 & ke-1 & $\begin{array}{c}\text { Cerah } \\
\text { Berawan }\end{array}$ & 28.66 & 33 & 22 \\
\hline 2 & ke-2 & $\begin{array}{c}\text { Cerah } \\
\text { Terik }\end{array}$ & 30.44 & 37 & 23 \\
\hline 3 & ke-3 & Mendung & 26.95 & 31 & 23 \\
\hline 4 & ke-4 & Mendung & 27.10 & 30 & 24 \\
\hline 5 & ke-5 & Mendung & 27 & 31 & 23 \\
\hline 6 & ke-6 & $\begin{array}{c}\text { Cerah } \\
\text { Berawan }\end{array}$ & 28.89 & 33 & 25 \\
\hline 7 & ke-7 & $\begin{array}{c}\text { Cerah } \\
\text { Berawan }\end{array}$ & 27.86 & 32 & 24 \\
\hline
\end{tabular}

TABEL II. RATA - RATA, MAKSIMUM DAN MINIMUM SUHU AIR DATA OBSERVASI

\begin{tabular}{|c|c|c|c|c|c|}
\hline No & Hari & $\begin{array}{c}\text { Kondisi } \\
\text { Cuaca }\end{array}$ & $\begin{array}{c}\text { Suhu Air } \\
\text { Rata - } \\
\text { rata }\left({ }^{\mathbf{O}} \mathbf{C}\right)\end{array}$ & $\begin{array}{c}\text { Suhu Air } \\
\text { Maksimum } \\
\left({ }^{\mathbf{O}} \mathbf{C}\right)\end{array}$ & $\begin{array}{c}\text { Suhu Air } \\
\text { Minimum } \\
\left({ }^{\mathbf{O}} \mathbf{C}\right)\end{array}$ \\
\hline 1 & ke-1 & $\begin{array}{c}\text { Cerah } \\
\text { Berawan }\end{array}$ & 28.97 & 33 & 22 \\
\hline 2 & ke-2 & $\begin{array}{c}\text { Cerah } \\
\text { Terik }\end{array}$ & 30.42 & 36 & 19 \\
\hline 3 & ke-3 & Mendung & 27 & 32 & 20 \\
\hline 4 & ke-4 & Mendung & 27.47 & 32 & 22 \\
\hline 5 & ke-5 & Mendung & 27.01 & 32 & 21 \\
\hline 6 & ke-6 & $\begin{array}{c}\text { Cerah } \\
\text { Berawan }\end{array}$ & 27.28 & 30 & 24 \\
\hline 7 & ke-7 & $\begin{array}{c}\text { Cerah } \\
\text { Berawan }\end{array}$ & 27.03 & 31 & 22 \\
\hline
\end{tabular}

Berdasarkan Tabel II, hari ke -2 memiliki nilai suhu air rata - rata terbesar dan nilai maksimum suhu air terbesar jika dibandingkan dengan data pada hari - hari lainnya yaitu $30.42{ }^{\circ} \mathrm{C}$ dan $36{ }^{\circ} \mathrm{C}$. Peningkatan suhu air yang tinggi ini disebabkan karena pengaruh cuaca cerah dan intensitas cahaya matahari yang tinggi serta adanya peningkatan suhu udara di sekitar greenhouse. Pada hari ke -3 memiliki nilai suhu air rata - rata terkecil yaitu $27{ }^{\circ} \mathrm{C}$, sedangkan nilai suhu air maksimum terkecil dicapai pada hari ke -6 yaitu $30{ }^{\mathrm{O}} \mathrm{C}$.

TABEL III. RATA - RATA, MAKSIMUM DAN MINIMUM KELEMBABAN UDARA DATA OBSERVASI

\begin{tabular}{|c|c|c|c|c|c|}
\hline No & Hari & $\begin{array}{c}\text { Kondisi } \\
\text { Cuaca }\end{array}$ & $\begin{array}{c}\text { Kelembaban } \\
\text { Rata - rata } \\
(\%)\end{array}$ & $\begin{array}{c}\text { Kelemb } \\
\text { aban } \\
\text { Maksim } \\
\text { um (\%) }\end{array}$ & $\begin{array}{c}\text { Kelemba } \\
\text { ban } \\
\text { Minimu } \\
\text { m (\%) }\end{array}$ \\
\hline 1 & ke-1 & $\begin{array}{c}\text { Cerah } \\
\text { Berawan }\end{array}$ & 72.45 & 99 & 57 \\
\hline 2 & ke-2 & $\begin{array}{c}\text { Cerah } \\
\text { Terik }\end{array}$ & 64.19 & 99 & 42 \\
\hline 3 & ke-3 & Mendung & 80.45 & 99 & 69 \\
\hline 4 & ke-4 & Mendung & 88.14 & 99 & 71 \\
\hline 5 & ke-5 & Mendung & 80.42 & 99 & 69 \\
\hline 6 & ke-6 & $\begin{array}{c}\text { Cerah } \\
\text { Berawan }\end{array}$ & 76.35 & 96 & 60 \\
\hline 7 & ke-7 & $\begin{array}{c}\text { Cerah } \\
\text { Berawan }\end{array}$ & 78.28 & 98 & 61 \\
\hline
\end{tabular}

TABEL IV. PENENTUAN NILAI AMBANG BATAS

\begin{tabular}{|c|c|c|c|c|c|}
\hline No & Hari & $\begin{array}{c}\text { Kondisi } \\
\text { Cuaca }\end{array}$ & $\begin{array}{c}\text { Suhu Udra } \\
\text { Rata - rata } \\
\left({ }^{\circ} \mathrm{C}\right)\end{array}$ & $\begin{array}{c}\text { Suhu Air } \\
\text { Rata - } \\
\text { rata }\left({ }^{\circ} \mathrm{C}\right)\end{array}$ & $\begin{array}{c}\text { Kelembab } \\
\text { an Rata - } \\
\text { rata }(\%)\end{array}$ \\
\hline 1 & ke-1 & $\begin{array}{c}\text { Cerah } \\
\text { Berawan }\end{array}$ & 28.66 & 28.97 & 72.45 \\
\hline 2 & ke-2 & $\begin{array}{l}\text { Cerah } \\
\text { Terik }\end{array}$ & 30.44 & 30.42 & 64.19 \\
\hline 3 & ke-3 & Mendung & 26.95 & 27 & 80.45 \\
\hline 4 & ke-4 & Mendung & 27.10 & 27.47 & 88.14 \\
\hline 5 & ke-5 & Mendung & 27 & 27.01 & 80.42 \\
\hline 6 & ke-6 & $\begin{array}{c}\text { Cerah } \\
\text { Berawan }\end{array}$ & 28.89 & 27.28 & 76.35 \\
\hline 7 & ke-7 & $\begin{array}{c}\text { Cerah } \\
\text { Berawan }\end{array}$ & 27.86 & 27.03 & 78.28 \\
\hline \multicolumn{3}{|c|}{ Batas Atas } & 30.44 & 30.42 & 88.14 \\
\hline \multicolumn{3}{|c|}{ Batas Bawah } & 26.95 & 27 & 64.19 \\
\hline
\end{tabular}

Data yang ditunjukkan pada Tabel III hari ke -2 , memiliki nilai kelembaban rata - rata terkecil dan nilai minimum kelembaban terkecil dibandingkan dengan data pada hari - hari lainnya yaitu $64.19 \%$ dan $42 \%$. Sedangkan Pada hari ke - 4 memiliki nilai kelembaban udara rata - rata terbesar yaitu $88.14 \%$ dan nilai kelembaban minimum terbesar yaitu $71 \%$.

Berdasarkan pada Tabel IV maka nilai ambang atas dan bawah suhu udara dan suhu air pada penelitian ini adalah $27{ }^{\circ} \mathrm{C}$ dan $30{ }^{\circ} \mathrm{C}$, sedangkan nilai ambang batas atas dan bawah kelembaban udara adalah $64 \%$ dan $88 \%$. Penentuan nilai ambang batas dapat dirumuskan sebagai berikut:

$$
\begin{aligned}
& \text { Batas Atas }=\Sigma \operatorname{Max} \Sigma(\bar{x}) \\
& \text { Batas Bawah }=\Sigma \operatorname{Min} \Sigma(\bar{x})
\end{aligned}
$$

Keterangan:

- Batas Atas merupakan nilai maksimum berdasarkan nilai rata - rata data observasi harian suhu udara, suhu air dan kelembaban udara.

- Batas Bawah merupakan nilai minimum berdasarkan nilai rata - rata data observasi harian suhu udara, suhu air dan kelembaban udara.

\section{A.4. Realisasi Pembangunan Database}

Dalam realisasi pembangunan database pada penelitian Rancang Bangun Sistem Conditioning Udara Berbasis IoT pada Studi Kasus Tanaman Selada Hidroponik ini, perangkat lunak untuk manajemen basis data SQL yang digunakan yaitu perangkat lunak MYSQL. Pada database yang dibangun terdiri dari empat tabel atau entitas, yaitu tabel perangkat, tabel parameter, tabel pengukuran dan tabel petani. Tabel perangkat berelasi dengan tabel pengukuran dan tabel parameter dengan kolom id_perangkat sebagai penghubung atau foreign key pada tabel pengukuran dan tabel parameter. Berikut realisasi tabel - tabel yang telah dibuat dalam pembangunan database sistem yang diberi nama "hidroponik" seperti yang terlihat pada Gambar 7. 

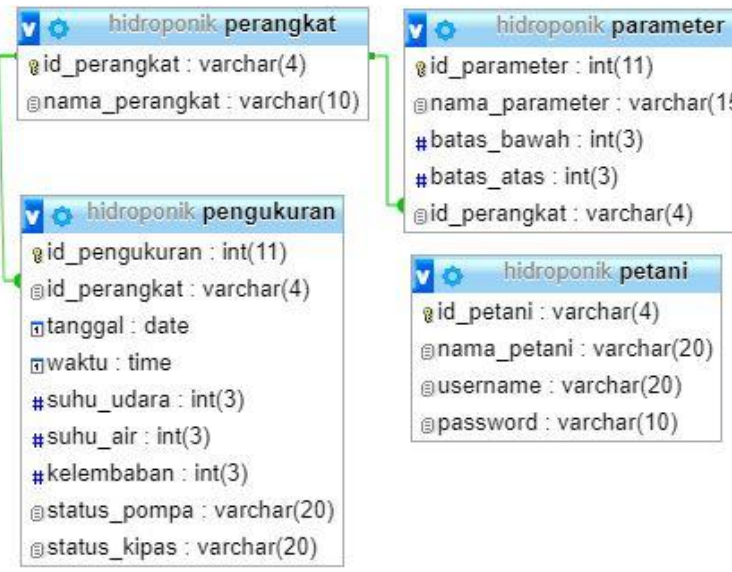

gid_parameter : int(11)

gnama_parameter : $\operatorname{varchar}(15)$

\#batas_bawah : int(3)

\# batas_atas : int( 3 )

_ id_perangkat : varchar(4)

y hidroponik petani
i id_petani : varchar(4)
onama_petani : $\operatorname{varchar}(20)$
gusername : varchar(20)
; password : varchar(10)

Gambar 7. Realisasi Pembangunan Database

\section{A.5. Realisasi Web Sistem Conditioning Udara}

Dalam pembuatan web sistem conditioning udara berbasis IoT pada Studi Kasus Tanaman Selada Hidroponik digunakan bahasa PHP dan dengan framework codeigniter. Berikut ini adalah contoh realisasi dari interface untuk halaman dashboard yang menampilkan pengukuran suhu udara, suhu air, kelembaban udara serta status relay terkini pada sistem web conditioning udara berbasis IoT pada studi kasus tanaman selada hidroponik seperti pada Gambar 8.
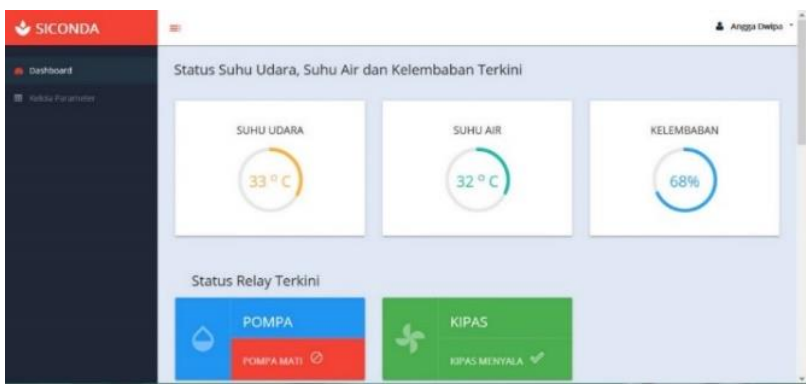

Gambar 8. Realisasi Web Sistem Conditioning Udara

\section{A.6. Realisasi Pembangunan Komunikasi Protokol MQTT}

Komunikasi protokol MQTT pada Sistem Conditioning Udara berbasis IoT pada Studi Kasus Tanaman Selada Hidroponik dibangun sesuai dengan rancangan komunikasi MQTT pada Gambar 5. Komunikasi protokol MQTT pada sistem dibangun dengan menggunakan bahasa pemrograman python yang berperan sebagai MQTT client. Program python ini terdiri dari publisher dan subscriber yang dijalankan pada CMD. Realisasinya dapat dilihat pada Gambar 9.
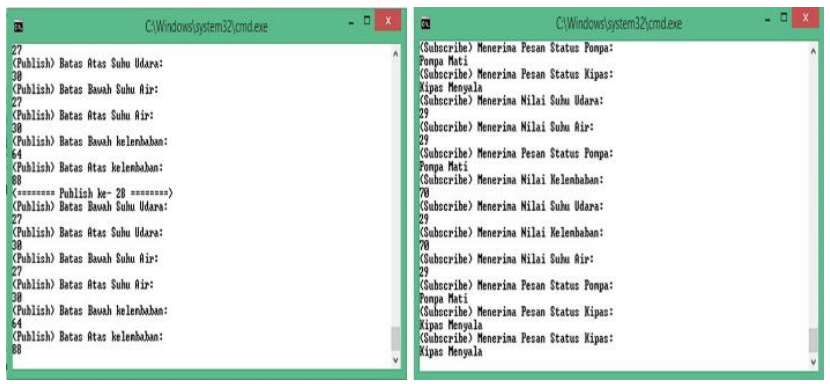

Gambar 9. Realisasi MQTT Client Sebagai Publisher dan Subscriber

\section{B. Pengujian Sistem}

Pengujian sistem merupakan proses pengeksekusian sistem perangkat keras dan lunak untuk menentukan bahwa sistem telah sesuai dengan yang diharapkan peneliti. Pada pengujian sistem dibagi menjadi 2 tahap, yaitu pertama dilakukan pengujian terhadap fungsi dari alat sistem conditioning udara yang telah dibuat dan tahap kedua adalah pengujian terhadap fungsi dari sistem web. Berikut merupakan hasil pengujian yang telah dilakukan pada implementasi Sistem Conditioning Udara berbasis IoT pada Studi Kasus Tanaman Selada Hidroponik.

\section{B.1. Hasil Pengujian Sensor DHT22}

Pengujian sensor DHT22 ini, sensor ditempatkan pada greenhouse untuk mengukur suhu dan kelembaban udara. Hasil pembacaan sensor DHT22 kemudian dibandingkan dengan termometer dan hygrometer digital. Hasil pengujian sensor DHT22 dapat dilihat pada Tabel V dan Tabel VI.

TABEL V. HASIL PENGUJIAN SUHU UDARA SENSOR DHT22

\begin{tabular}{|c|c|c|c|}
\hline No & $\begin{array}{c}\text { Termometer } \\
\left({ }^{\mathbf{O}} \mathbf{C}\right)\end{array}$ & $\begin{array}{c}\text { Sensor } \\
\mathbf{D H T 2 2} \\
\left({ }^{\mathbf{O}} \mathbf{C}\right)\end{array}$ & $\begin{array}{c}\text { Galat } \\
\text { Relatif } \\
(\boldsymbol{\%})\end{array}$ \\
\hline 1 & 21.7 & 22.1 & 1.48 \\
\hline 2 & 25.1 & 25.9 & 3.18 \\
\hline 3 & 28.2 & 28.6 & 1.41 \\
\hline 4 & 32.1 & 31.2 & 2.80 \\
\hline 5 & 34.0 & 33.1 & 2.64 \\
\hline \multicolumn{3}{|c|}{ Rata - rata } & 2.37 \\
\hline
\end{tabular}

TABEL VI. HASIL PENGUJIAN KELEMBABAN UDARA SENSOR DHT 22

\begin{tabular}{|c|c|c|c|}
\hline No & $\begin{array}{c}\text { Hygrometer } \\
(\boldsymbol{\%})\end{array}$ & $\begin{array}{c}\text { Sensor } \\
\text { DHT22 } \\
(\boldsymbol{\%})\end{array}$ & $\begin{array}{c}\text { Galat } \\
\text { Relatif } \\
(\boldsymbol{\%})\end{array}$ \\
\hline 1 & 97 & 99 & 3.09 \\
\hline 2 & 79 & 82 & 3.79 \\
\hline 3 & 75 & 77 & 4.0 \\
\hline 4 & 66 & 65 & 1.51 \\
\hline 5 & 58 & 57 & 1.72 \\
\hline \multicolumn{3}{|c|}{ Rata - rata } \\
\hline
\end{tabular}

\section{B.2. Hasil Pengujian Sensor DS18B20}

Pengujian sensor DS18B20 atau sensor suhu air ini, sensor ditempatkan pada pipa media tanam greenhouse untuk mengukur suhu air. Hasil pembacaan sensor DS18B20 kemudian dibandingkan dengan termometer digital. Hasil pengujian dapat dilihat pada Tabel VII.

TABEL VII. HASIL PENGUJIAN SUHU AIR SENSOR DS18B20

\begin{tabular}{|c|c|c|c|}
\hline No & $\begin{array}{c}\text { Termometer } \\
\left({ }^{\mathbf{O}} \mathbf{C}\right)\end{array}$ & $\begin{array}{c}\text { Sensor } \\
\text { DHT22 } \\
\left({ }^{\mathbf{O}} \mathbf{C}\right)\end{array}$ & $\begin{array}{c}\text { Galat } \\
\text { Relatif } \\
(\boldsymbol{\%})\end{array}$ \\
\hline 1 & 21.3 & 22.1 & 3.75 \\
\hline 2 & 23.4 & 24.2 & 3.41 \\
\hline 3 & 27.3 & 27.7 & 1.46 \\
\hline 4 & 32.2 & 31.3 & 2.79 \\
\hline 5 & 34.4 & 33.5 & 2.61 \\
\hline \multicolumn{3}{|c|}{ Rata - rata } & 2.80 \\
\hline
\end{tabular}


Pengujian pada sensor DHT22 dan DS18B20 telah bekerja dengan baik. Nilai rata-rata galat yang dihasilkan dibawah 5\%, jadi ini masih berada pada nilai toleransi [10].

\section{B.3. Hasil Pengujian Modul Relay}

Pengujian modul relay ini bertujuan untuk mengetahui bahwa relay telah berfungsi dengan baik dalam menyalakan dan mematikan aktuator. Pengujian modul relay dapat dilihat pada Tabel VIII.

TABEL VIII. HASIL PENGUJIAN MODUL RELAY

\begin{tabular}{|c|c|c|c|c|}
\hline No & $\begin{array}{c}\text { Komponen } \\
\text { Pengujian }\end{array}$ & Input & $\begin{array}{c}\text { Kondisi } \\
\text { Relay }\end{array}$ & $\begin{array}{c}\text { Kondisi } \\
\text { Aktuator }\end{array}$ \\
\hline \multirow{2}{*}{1} & \multirow{2}{*}{ Relay 1 } & High & Off & Pompa Mati \\
\cline { 3 - 5 } & & Low & On & Pompa Menyala \\
\hline \multirow{2}{*}{2} & \multirow{2}{*}{ Relay 2} & High & Off & Kipas Mati \\
\cline { 3 - 5 } & Low & On & Kipas Menyala \\
\hline
\end{tabular}

Tabel VIII menunjukkan bahwa relay sudah bekerja dengan baik. Dikarenakan relay diposisikan pada normally open dan bekerja pada aktif low, apabila input relay di-set high maka kondisi relay akan off dan aktuator dalam kondisi mati. Sebaliknya, jika input relay di-set low maka kondisi relay akan on dan aktuator dalam kondisi menyala.

\section{B.4. Hasil Pengujian Keseluruhan Sistem}

Pengujian keseluruhan sistem dilakukan selama 1 minggu terhitung dari tanggal 05 Agustus sampai 11 Agustus 2019. Sensor - sensor akan melakukan pembacaan tingkat suhu dan kelembaban udara disekitar greenhouse serta tingkat suhu air pada pipa media tanam tanaman selada hidroponik. Pada tahap pengujian ini nilai ambang batas bawah dan ambang batas atas suhu udara dan suhu air di-set menjadi $27^{\circ} \mathrm{C}$ dan $30^{\circ} \mathrm{C}$. Sedangkan nilai ambang batas bawah dan ambang batas atas kelembaban udara diset menjadi $64 \%$ dan $88 \%$. Seluruh data pembacaan sensor dan status relay akan dikirimkan ke database dan ditampilkan ke sistem web serta LCD. Untuk lebih jelasnya dapat dilihat pada Gambar 10 dan Gambar 11.

Pada data ke 11 sampai ke 15 status pompa dan status kipas telah menunjukkan keputusan yang benar yaitu pompa mati dan kipas mati karena nilai suhu udara dan suhu air belum melewati ambang batas atas, sedangkan nilai kelembaban udara belum melewati ambang batas bawah. Pada data ke 16 sampai ke 20 status pompa dan status kipas juga telah menunjukkan keputusan yang benar yaitu pompa menyala dan kipas mati karena nilai kelembaban udara telah melewati nilai ambang batas bawah, sedangkan nilai suhu udara dan suhu air belum melewati ambang batas atas.

Pada data ke 44 dan 45 status pompa dan status kipas telah menunjukkan keputusan yang benar yaitu pompa mati dan kipas menyala karena nilai suhu udara dan suhu air telah melewati nilai ambang batas atas, sedangkan nilai kelembaban tidak melewati nilai ambang batas bawah. Data ke 46 sampai ke 50 telah menunjukkan keputusan yang benar yaitu pompa menyala dan kipas menyala karena nilai suhu udara dan suhu air telah melewati nilai ambang batas atas, sedangkan nilai kelembaban telah melewati nilai ambang batas bawah.

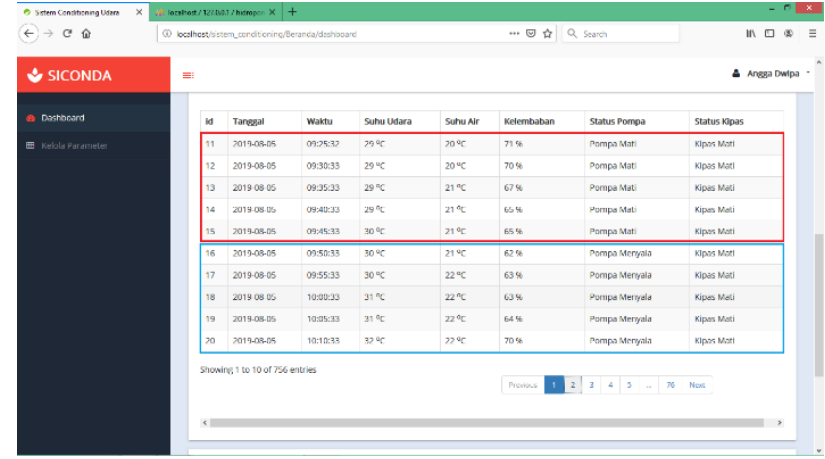

Gambar 10. Hasil Pengujian Keseluruhan Sistem Data ke 11-20

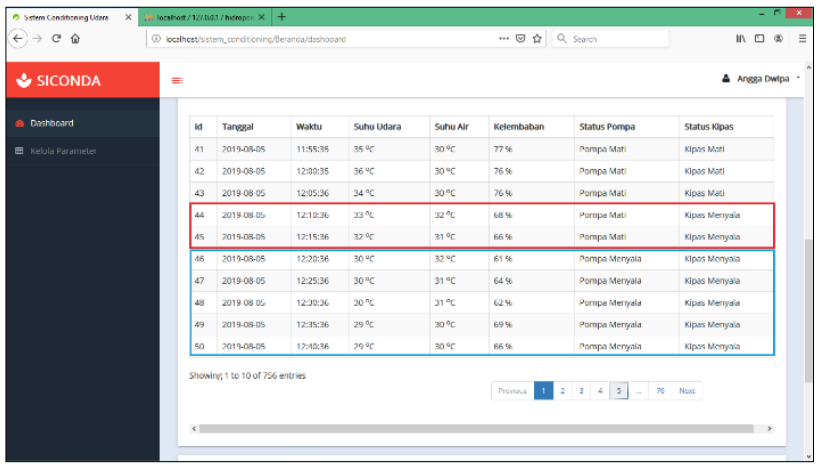

Gambar 11. Hasil Pengujian Keseluruhan Sistem Data ke 41-50

\section{B.5. Hasil Pengujian Web Sistem}

Pada pengujian web Sistem Conditioning Udara berbasis IoT pada Studi Kasus Tanaman Selada Hidroponik dilakukan dengan menggunaakan metode black box untuk menguji fungsi - fungsi yang ada pada sistem. Fungsi fungsi yang diuji adalah Fungsi Login Pengguna, Fungsi Mengubah Data Parameter dan Fungsi Filter Data Grafik.

Dari hasil pengujian menghasilkan kesimpulan valid, yaitu semua fungsi yang diujikan sudah berjalan dengan baik sesuai yang diharapkan.

\section{Analisis Data Pengujian}

Data pada pengujian keseluruhan sistem diambil selama satu minggu terhitung dari tanggal 05 Agustus sampai 11 Agustus 2019 mulai dari pukul 08.00 WITA sampai pukul 17.00 WITA. Data disimpan ke database dengan delay setiap 5 menit.

Grafik pada Gambar 12 merupakan grafik hubungan suhu udara, suhu air dan kelembaban udara terhadap waktu berdasarkan data pengujian pada tanggal 05 Agustus 2019 dengan kondisi cuaca cerah terik seperti yang ditunjukkan pada Gambar 12. Data pengujian saat pukul 12.00 nilai suhu udara mengalami peningkatan terbesar mencapai 36 ${ }^{\mathrm{O}} \mathrm{C}$ dan berangsur menurun pada pukul 12.20 menjadi 30 ${ }^{\mathrm{O}} \mathrm{C}$. Pengujian pada pukul 12.45 nilai suhu air mengalami peningkatan terbesar mencapai $33{ }^{\mathrm{O}} \mathrm{C}$ dan berangsur menurun pada pukul 12.55 menjadi $29^{\circ} \mathrm{C}$. Data pengujian pada pukul 14.25 nilai kelembaban mengalami penurunan mencapai $60 \%$ dan berangsur meningkat pada pukul 14.45 menjadi $80 \%$. 


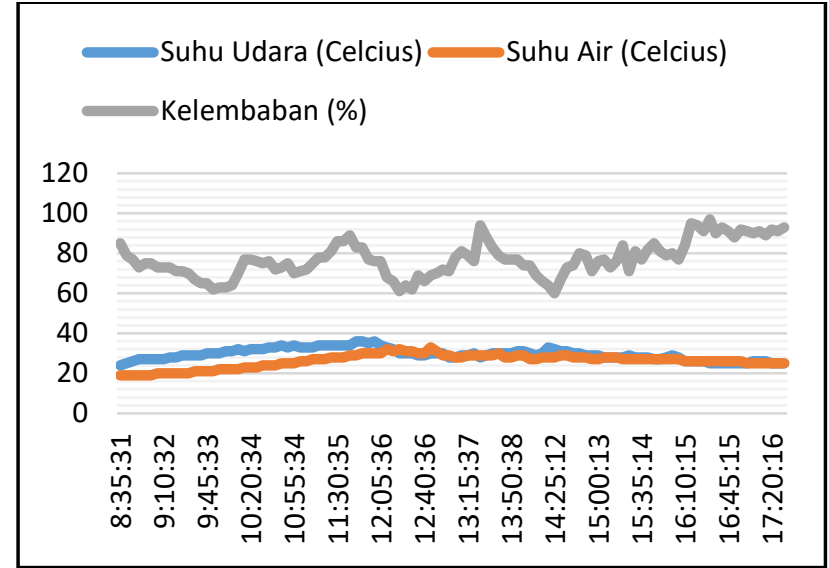

Gambar 12. Grafik Data Pengujian Sistem 05 Agustus 2019

TABEL IX. RATA - RATA, MAKSIMUM DAN MINIMUM SUHU UDARA DATA PENGUJIAN

\begin{tabular}{|c|c|c|c|c|c|}
\hline No & Hari & $\begin{array}{c}\text { Kondisi } \\
\text { Cuaca }\end{array}$ & $\begin{array}{c}\text { Suhu } \\
\text { Udara } \\
\text { Rata }- \\
\text { rata }\left({ }^{\mathbf{O}} \mathbf{C}\right)\end{array}$ & $\begin{array}{c}\text { Suhu } \\
\text { Udara } \\
\text { Maksim } \\
\text { um }\left({ }^{\mathbf{0}} \mathbf{C}\right)\end{array}$ & $\begin{array}{c}\text { Suhu } \\
\text { Udara } \\
\text { Minimum } \\
\left({ }^{\mathbf{}} \mathbf{C}\right)\end{array}$ \\
\hline 1 & ke-1 & Cerah Terik & 29.49 & 36 & 24 \\
\hline 2 & ke-2 & Cerah Terik & 30.72 & 36 & 24 \\
\hline 3 & ke-3 & Cerah Terik & 29.72 & 35 & 23 \\
\hline 5 & ke-4 & Cerah Terik & 30.03 & 34 & 24 \\
\hline 5 & ke-5 & Cerah Terik & 29.71 & 36 & 25 \\
\hline 7 & ke-6 & Cerah Terik & 29.69 & 34 & 24 \\
\hline
\end{tabular}

Pada Tabel IX merupakan nilai rata - rata, nilai maksimum dan nilai minimum suhu udara berdasarkan data hasil pengujian yang dilakukan selama satu minggu dengan kondisi cuaca cerah terik dan cerah berawan. Terdapat perbedaan pada data hasil observasi Tabel I dihari ke -2 jika dibandingkan dengan data hasil pengujian pada hari ke - 1 sampai hari ke -6 dengan kondisi cuaca yang sama yaitu cerah terik. Berdasarkan data hasil observasi, suhu udara rata - rata yang mencapai nilai $30.44{ }^{\mathrm{O}} \mathrm{C}$ dapat diturunkan saat pengujian sistem menjadi $30.03{ }^{\circ} \mathrm{C}$ sampai $29.49^{\circ} \mathrm{C}$. Kemudian suhu udara maksimum yang mencapai $37{ }^{\circ} \mathrm{C}$ pada data observasi dapat diturunkan saat pengujian sistem menjadi $36{ }^{\circ} \mathrm{C}$ sampai $34{ }^{\circ} \mathrm{C}$.

TABEL X. RATA - RATA, MAKSIMUM DAN MINIMUM SUHU AIR DATA PENGUJIAN

\begin{tabular}{|c|c|c|c|c|c|}
\hline No & Hari & $\begin{array}{c}\text { Kondisi } \\
\text { Cuaca }\end{array}$ & $\begin{array}{c}\text { Suhu Air } \\
\text { Rata- } \\
\text { rata }\left({ }^{\mathbf{O}} \mathbf{C}\right)\end{array}$ & $\begin{array}{c}\text { Suhu } \\
\text { Air } \\
\text { Maksim } \\
\text { um }\left({ }^{\mathbf{O}} \mathbf{C}\right)\end{array}$ & $\begin{array}{c}\text { Suhu Air } \\
\text { Minimum } \\
\left({ }^{\mathbf{O}} \mathbf{C}\right)\end{array}$ \\
\hline 1 & ke-1 & Cerah Terik & 26.14 & 33 & 19 \\
\hline 2 & ke-2 & Cerah Terik & 26.31 & 33 & 19 \\
\hline 3 & ke-3 & Cerah Terik & 26.45 & 32 & 19 \\
\hline 4 & ke-4 & Cerah Terik & 26.24 & 31 & 20 \\
\hline 5 & ke-5 & Cerah Terik & 27 & 32 & 21 \\
\hline 6 & ke-6 & Cerah Terik & 27.33 & 32 & 21 \\
\hline 7 & ke-7 & $\begin{array}{c}\text { Cerah } \\
\text { Berawan }\end{array}$ & 27.05 & 31 & 19 \\
\hline
\end{tabular}

Tabel X merupakan nilai rata - rata, nilai maksimum dan nilai minimum suhu air berdasarkan data hasil pengujian yang dilakukan selama satu minggu. Terdapat perbedaan pada data hasil observasi Tabel II di hari ke - 2 dengan data hasil pengujian pada hari ke - 1 sampai hari ke - 6 dengan kondisi cuaca yang sama yaitu cerah terik. Berdasarkan hasil observasi, suhu air rata - rata yang mencapai nilai $30.42{ }^{\circ} \mathrm{C}$ dapat diturunkan saat pengujian sistem menjadi $27.33{ }^{\circ} \mathrm{C}$ sampai $26.14{ }^{\circ} \mathrm{C}$. Kemudian suhu air maksimum yang mencapai $36^{\circ} \mathrm{C}$ dapat diturunkan saat pengujian sistem menjadi $33{ }^{\circ} \mathrm{C}$ sampai $31{ }^{\circ} \mathrm{C}$.

TABEL XI. RATA - RATA, MAKSIMUM DAN MINIMUM KELEMBABAN UDARA DATA OBSERVASI

\begin{tabular}{|c|c|c|c|c|c|}
\hline No & Hari & $\begin{array}{c}\text { Kondisi } \\
\text { Cuaca }\end{array}$ & $\begin{array}{c}\text { Kelemba } \\
\text { ban Rata } \\
-\mathbf{r a t a} \\
(\boldsymbol{\%})\end{array}$ & $\begin{array}{c}\text { Kelemb } \\
\text { aban } \\
\text { Maksim } \\
\text { um }(\%)\end{array}$ & $\begin{array}{c}\text { Kelemba } \\
\text { ban } \\
\text { Minimu } \\
\mathbf{m}(\boldsymbol{\%})\end{array}$ \\
\hline 1 & ke-1 & Cerah Terik & 77.08 & 97 & 60 \\
\hline 2 & ke-2 & Cerah Terik & 75.87 & 99 & 55 \\
\hline 3 & ke-3 & Cerah Terik & 82.51 & 99 & 56 \\
\hline 4 & ke-4 & Cerah Terik & 80.24 & 99 & 57 \\
\hline 5 & ke-5 & Cerah Terik & 81.50 & 99 & 57 \\
\hline 6 & ke-6 & Cerah Terik & 79.70 & 99 & 50 \\
\hline 7 & ke-7 & $\begin{array}{c}\text { Cerah } \\
\text { Berawan }\end{array}$ & 87.04 & 99 & 59 \\
\hline
\end{tabular}

Data yang ditunjukkan Tabel XI merupakan nilai rata rata, nilai maksimum dan nilai minimum kelembaban udara berdasarkan hasil pengujian yang dilakukan selama satu minggu. Terdapat perbedaan pada data hasil observasi Tabel III dihari ke - 2 jika dibandingkan dengan data hasil pengujian pada hari ke -1 sampai hari ke -6 dengan kondisi cuaca yang sama yaitu cerah terik. Berdasarkan data hasil observasi, kelembaban rata - rata pada data observasi yang mencapai nilai $64.19 \%$ dapat ditingkatkan saat pengujian sistem menjadi $75.87 \%$ sampai $82.51 \%$. Kemudian kelembaban udara minimum yang mencapai $42 \%$ dapat ditingkatkan saat pengujian sistem menjadi $50 \%$ sampai $60 \%$.

Hal ini disebabkan karena pengaruh dari penerapan aktuator pompa sprinkler dan kipas angin pada saat pengujian sistem sehingga variabel lingkungan suhu dan kelembaban udara serta suhu air dapat dikondisikan.

\section{KESIMPULAN DAN SARAN}

\section{A. Kesimpulan}

Berdasarkan analisa dan pembahasan, dapat diambil kesimpulan antara lain :

1. Sistem yang dibangun telah dapat melakukan pengukuran dan pengkondisian suhu dan kelembaban udara serta suhu air pada greenhouse secara otomatis menggunakan Wemos D1 Mini sebagai mikrokontroler dengan data pengujian yang dihasilkan dari pukul 08.00 sampai 17.00 dalam satu minggu.

2. Sistem web yang dibangun telah dapat melakukan monitoring dengan menampilkan data pengukuran terkini dan data berupa tabel serta grafik berdasarkan 
3. tanggal dan waktu serta melakukan pengaturan parameter ambang batas.

4. Komunikasi data menggunakan protokol MQTT telah berjalan dengan baik, dimana MQTT broker yang digunakan adalah "broker.hivemq.com" merupakan broker online yang dapat diakses secara gratis.

5. Berdasarkan perbandingan antara data hasil observasi dan data hasil pengujian dengan kondisi cuaca cerah terik, dapat disimpulkan bahwa suatu suhu udara dan suhu air untuk nilai rata - rata dan maksimum pada pengujian menghasilkan nilai yang lebih rendah dibandingkan dengan data hasil observasi. Sedangkan nilai kelembaban udara untuk nilai rata - rata dan minimum pada pengujian lebih tinggi dibandingkan dengan data hasil observasi. Hal ini disebabkan karena pengaruh dari penerapan aktuator pompa sprinkler kipas angin pada saat pengujian sistem sehingga variabel lingkungan suhu dan kelembaban udara serta suhu air dapat dikondisikan

6. Pola data pada hasil observasi dan pengujian sistem menunjukkan bahwa nilai suhu udara berbanding lurus dengan suhu air, sedangkan nilai kelembaban udara berbanding terbalik dengan suhu udara.

7. Pengaruh cuaca dan intensitas cahaya matahari juga sangat berdampak terhadap perubahan tingkat suhu dan kelembaban udara serta suhu air pada greenhouse tanaman selada hidroponik.

\section{B. Saran}

Jika dilakukan penelitian lebih lanjut tentang penelitian

ini dapat mempertimbangkan saran - saran sebagai berikut:

1. Sistem ini diharapkan dapat dikembangkan tidak hanya untuk tanaman selada hidroponik namun juga untuk jenis tanaman lainnya dengan metode hidroponik di sebuah greenhouse pada suatu daerah tertentu.

2. Sistem ini diharapkan dapat dikembangkan dengan menambahkan fitur untuk mengkondisikan tingkat nutrisi dan $\mathrm{pH}$ air tanaman.

3. Dibutuhkan penambahan jumlah sprinkler agar air berupa embun halus yang disemprotkan dapat menjangkau seluruh ruang greenhouse tanaman selada hidroponik yang berukuran 4 meter x 3 meter x 3 meter sehingga tingkat kelembaban udara dapat dikendalikan lebih optimal.

\section{DAFTAR PUSTAKA}

[1] H. Mas'ud, "Sistem Hidroponik dengan Nutrisi dan Media Tanam Berbeda Terhadap Pertumbuhan dan Hasil Selada," Media Litbang Sulteng, vol. 2, no. 2, pp. 131-136, 2009.

[2] T. O. Muhadiansyah and S. A. Adimihardja, "Efektivitas Pencampuran Pupuk Organik Cair Dalam Nutrisi Hidroponik pada Pertumbuhan dan Produksi Tanaman Selada," Jurnal Agronida, vol. 2, no. 1, pp. 37-46, 2016.

[3] M. V. Sariayu, H. Priyatman, and B. W. Sanjaya, "Pengendalian Suhu dan Kelembaban pada Tanaman Selada dengan Sistem Aeroponik Berbasis Arduino Uno R3," Program Studi Teknik Elektro, Jurusan Teknik Elektro Fakultas Teknik Universitas Tanjungpura, 2017.

[4] I. M. A. Suyadnya, I. G. Agung, and P. Raka, "Sistem Monitoring Penetasan Telur Penyu Menggunakan Mikrokontroler NodeMCU ESP8266 dan Protokol MQTT dengan Notifikasi Berbasis Telegram Messenger," JCOSINE, vol. 2, no. 2, pp. 80-89, 2018.

[5] F. K. R. Mahfud, A. D. Afrizal, F. A. Pribadi, F. J. Pamungkas, and G. Y. Saputra, "Penerapan Protokol MQTT pada Teknologi Wan," Jurnal Informatika Mulawarman, vol. 12, no. 2, p. 69, 2018.

[6] R. R. Pambayun and Sumarna, "Otomatisasi Pengendalian Suhu pada Greenhouse,” Jurnal Fisika, vol. 7, no. 5, pp. 19, 2016.

[7] A. B. Setyawan, M. Hannats, and G. E. Setyawan, "Sistem Monitoring Kelembaban Tanah, Kelembaban Udara dan Suhu pada Lahan Pertanian Menggunakan Protokol MQTT," Jurnal Pengembangan Teknologi Informasi dan Ilmu Komputer Universitas Brawijaya, vol. 2, no. 12, pp. 7502-7508, 2018.

[8] D. M. Subrata, F. F. A, and R. Arafiyah, "Sistem Monitoring Parameter Suhu Cabe Merah dengan Sistem Aeroponik pada Greenhouse untuk Mendukung Ketahanan Pangan Nasional," Jurnal Teknik Mesin Untirta, vol. 4, no. 2, pp. 91-95, 2018.

[9] M. S. Asih, A. Z. Hasibuan, and N. I. Syahputri, "Pendingin Otomatis Akuarium Menggunakan Mikrokontroler," Jurnal Penelitian Teknik Informatika Universitas Prima Indonesia Medan, vol. 1, no. 1, pp. 6670, 2019.

[10] H. Suryawinata, D. Purwanti, and S. Sunardiyo, "Sistem Monitoring pada Panel Surya Menggunakan Data logger Berbasis ATmega 328 dan Real Time Clock DS1307," Jurnal Teknik Elektro, vol. 9, no. 1, pp. 30-36, 2017. 